\title{
MODEL AND SIMULATION OF A HOT- AIR DEHYDRATION SYSTEM OF FRUITS
}

\author{
Jhersson Castaño ${ }^{1}$, Darío Amaya ${ }^{2}$, Olga Ramos ${ }^{3}$ \\ ${ }^{1,2,3}$ Universidad Militar Nueva Granada, Bogotá Colombia \\ Faculty of Engineering

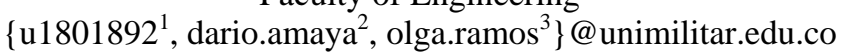

\begin{abstract}
The most used practice for food preservation is the dehydration, in particular, the heat-air dehydration which is theoldest method used nowadays. In this work, a mathematical model was developed to describe this behavior, always working in the linear region of the process of dehydration. The model proposed was implemented in MATLAB software with the Simulink tool and evaluated with a simulation CFD in SolidWorks. The behavior of the analytical model compared with the CFD simulation, showed a high variation for the values of final moisture in the food. This is due to the initial restrictions made for the model, especially, assume that the temperature inside the chamber is homogeneous. The model allows to vary all the features of the system and identify the behavior during the process.
\end{abstract}

Keywords: Hot-air Dehydration, analytical model, moisture content.

\section{Introduction}

The heat-air dehydration is one of the most used methods in the food industry, because of the relation of costprofit that is obtained by implementing it in the small production systems[1]. This model implies use a hot air flux at high temperature, which going extracting the moist in the food by evaporation. In this condition the food is subject to temperatures of $30^{\circ} \mathrm{C}$ y $70^{\circ} \mathrm{C}$ and final moistures content of $10 \%-2 \%$ wet-basis[2].

Nowadays, exist semi-empiric models that approach the dynamics dehydration based on numeric methods.Some examples are : Hii-Law-Cloke model, which is implemented to describe the dehydration of cocoa, making a combination of two standards (Page and two-term models)[3], the logarithmic, which is the best representation applied to apple pomace[4]and the CFD, where besides of general studies, specific and more detailed analysis canbe made[5].These models have a disadvantagewhen it comes to scale or apply to other systems,because these are closely related to the studyphenomenon.

Also, exists alternatives that are product of the new tools like computational neural networks or the fuzzy-logic algorithms [6], which have a highest approach to the behavior as long as data or computational resource be enough. otherwise, the application of this alternatives is reduced to laboratory or pharmaceutical industries[7].

An analytical model is a simple approach, focused in a resolution of the problem using ordinary differential equations (ODE). The ODE's have an advantage when it comes of speed and variability of their features[8],being more useful when it does not have a practical experiment available or when environment change[9].

\section{Materials and Methods}

The hot-air dehydration is a method that use flux of air at high temperatures, frequently above the ambient, to extract moisture by evaporation. This systems are described for phenomenon of mass transfer and energy transfer, Fick’s Law (Ec. 1) and Furrier Law (Ec. 2), respectively[10].

$$
\begin{aligned}
& J=-D \frac{d C}{d x} \\
& \dot{q}=-k \frac{d T}{d x}
\end{aligned}
$$

Where $\mathrm{D}$ is the diffusivity of fluid and $\mathrm{k}$ is the material conductivity. The heat transport is the dominant process for this dehydration, therefore, the flux corresponds to a convective transfer. Which is defined by developing the Furrier law (Ec. 1), how is presented in the equation (Ec.3).

$$
\dot{q}=h A \Delta T
$$

Where $h A$ is the thermal resistivity that faces the heat flux due to the gradient of temperatures $\Delta T$. 
The operating diagram shown in the Figure1,poses the basic system for a hot air dehydration. In this, a source of heat(Qe),aninput air flow (F)and a thermic load which the system is submitted by de air flow (Qf) are considered.

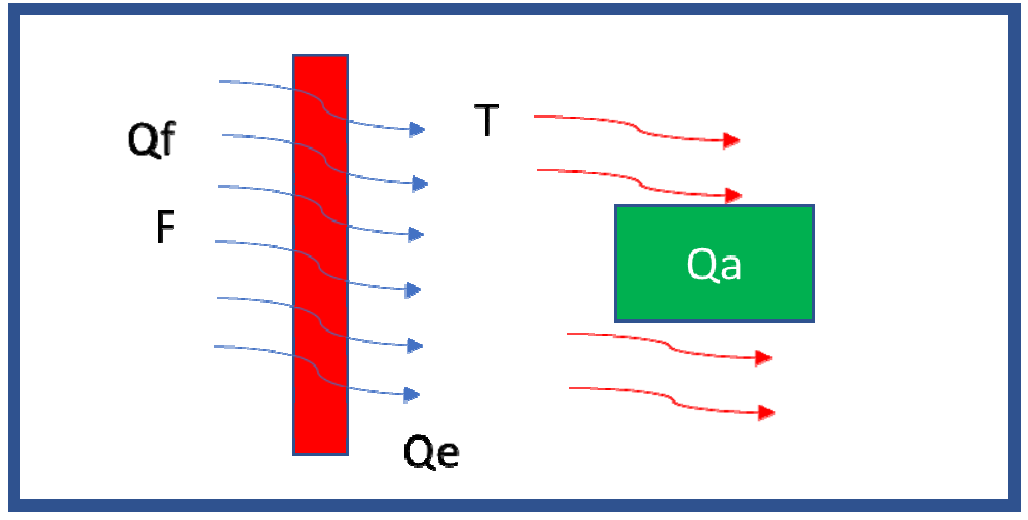

Figure1. Function diagram for the heat-air dehydration.

To model the system, some boundary restrictions are considered with the aim of restrict the dynamic of this.

- Full developed flux.

- Input and output fluxes are equal

- Output Temperature equals to the inside of the chamber temperature.

- Constantthermodynamicfeatures.

- The mass transfer occurs in the surface.

- Notsensibleheat.

Similarly, two phases are posed for the model of function, the first, is for the increase the air temperature inside the chamber and the second is for make the dehydration by evaporation whit the air heated previously(Figure 2).For the mathematical develop of the first phase the definition of conservative equation of mass and energy (Ec. 4) y (Ec. 5) are needed.

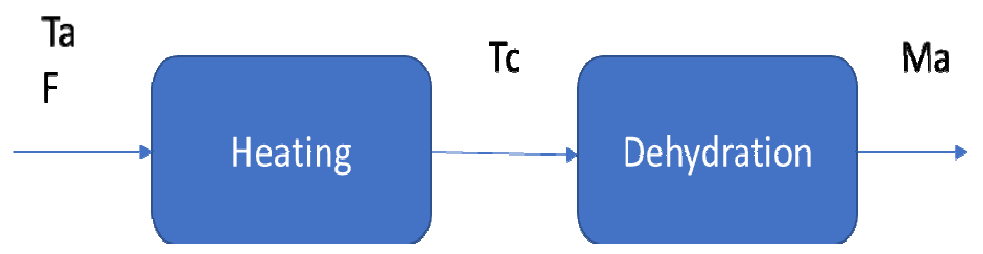

Figure2. Blocks diagram for the model of function.

$$
\begin{aligned}
E t & =E e-E s \quad \text { (Ec. 4) } \\
M t & =M e-M s \quad \text { (Ec. 5) }
\end{aligned}
$$

Where Et and Mt are the total energy and mass inside the system, that is affected by the differences between the input flux Eeand Me,versusthe output flux, Es and Ms. According with the boundary conditions, the system does not have an accumulation of mass, for this, the flux of output and input are equal and thus, the system, do not have a variation in the mas flux.

For the energy, the intern variation is in heat form and is determinate by the flux of input and output qe y qf(Ec. $6)$.

$$
\dot{Q}=q_{e}-q_{f}
$$

Where $q_{e}$ is de heat yielded by convection from the heat exchanger, at Tsup temperature, to the air at Ta and qf is the heat absorb by air at ambient temperature. The relation of each flux is shown in the equations (Ec. 7) y (Ec. 8).

$$
q_{e}=h A\left(T_{\text {sup }}-T_{c}\right)
$$




$$
q_{f}=\rho F C_{p}\left(T_{s}-T_{a}\right)
$$

Where Tc is the chamber temperature, $\mathrm{h}$ is the convective transfer coefficient, $\rho$ is the density of the fluid, $C_{p}$ is the specific constant of fluid and A is the area of the heat exchanger. The change in the energy it defined by the equation (Ec. 9) where $\mathrm{m}$ is the mass of air in the chamber and Tc is de output temperature.

$$
\dot{Q}=m C_{p} \frac{d T_{c}}{d t}
$$

As the output temperature was assumed equal to the inside temperature, the relation established is shown in the equation(Ec. 10), which will be dominant just until the air interacts with the mass of food.

$$
\begin{array}{ll}
m C_{p} \frac{d T}{d t}=q_{e}-q_{f} & \text { (Ec. 10) } \\
q_{e}=h A\left(T_{\text {sup }}-T\right) & \text { (Ec. 11) } \\
q_{f}=\rho F C_{p}\left(T-T_{a}\right) & \text { (Ec. 12) }
\end{array}
$$

The mass transfer dynamic is given by the Fick law (Ec. 1), though if it is consider that the extraction of water occurs by evaporation only, the transfer mechanism is given by the equation (Ec. 12), Where the $\mathrm{W}$ is the mass of water, $\mathrm{h}$ is the convective heat transfer coefficient of food-air, $\mathrm{A}$ is the food characteristic area and $\lambda$ is the latten heat of evaporation [11].

$$
-\frac{d W}{d t}=\frac{h A}{\lambda}\left(T-T_{\text {sat }}\right)
$$

Tomake the evaporation the dominant process in the extraction of water, the surface temperature must be equal to the wet-bulb or saturation temperature, this value is given by the psychometric charts which show the dynamic air-vapor[12].To found $h$ in the food and the heat exchanger, was used the forced-flow correlation of the Nusselt number at air defined velocity. The equation (Ec. 15)shown this relation for cylinders in cross-flow.

$$
\begin{gathered}
N u=\frac{h D}{k} \\
N u=c R e^{n} \operatorname{Pr}^{\frac{1}{3}} \\
R e=\frac{D u \rho}{\mu}
\end{gathered}
$$

The model shown in the Figure 3 is the implementation in MATLAB with the tool Simulink, which is execute during 40s for $8 \mathrm{~h}$ of simulation.

With de aim of validate the implementation of the model, a simulation in CFD was developed in the Software SolidWorks ${ }^{\circledR}$ with Flow Simulation tool. This simulation is executed during 3h to obtain 100s of simulation. The 3D geometry consists in a cube to represent the chamber that have the exchanger inside, simplify their geometry to horizontal cylinders, (Figure4).

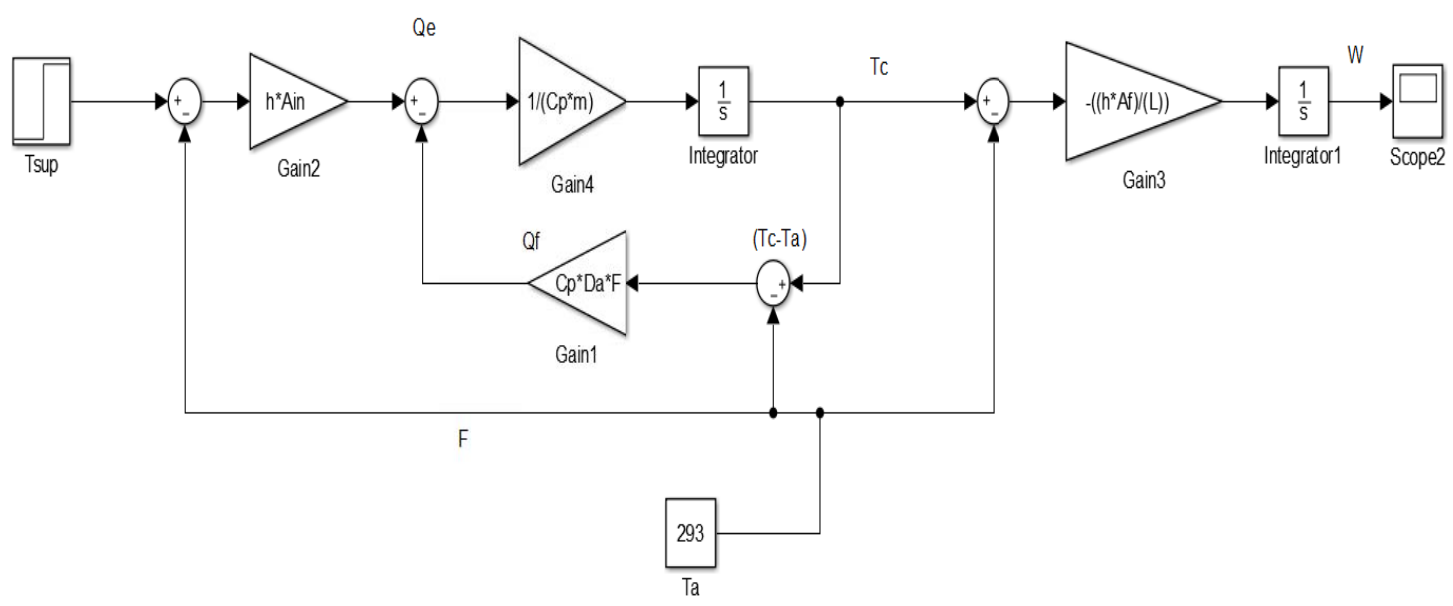

Figure 3. Implementation of the model in MATLAB Simulink tool. 


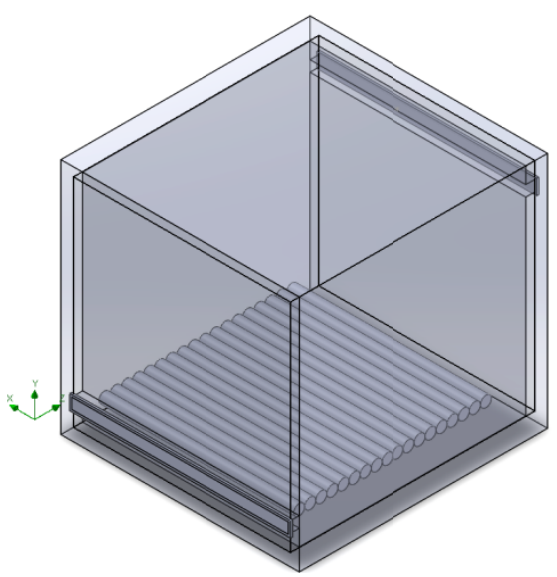

Figure4 3D model of the chamber dehydration used in SolidWorks.

The chamber is designed to obtain an output an input air flux with the same value, from this way make guaranty the parameters of the model propound. The positions of this outputs and inputs were defined searching that flow of air fill the entire chamber. The dimensions are represented in the Figure. 5 and related in the Table1.

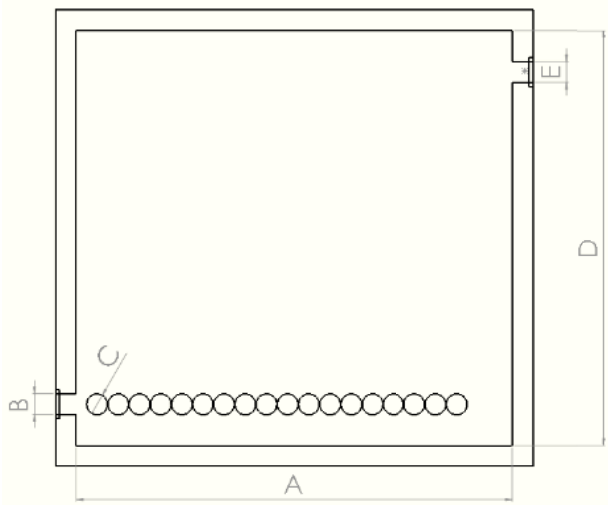

Figure. 5Dimensions of the chamber.

Table1 Dimensions of the chamber.

\begin{tabular}{|c|c|}
\hline Dimensión & Valor [mm] \\
\hline A & 210 \\
\hline B & 10 \\
\hline C & 10 \\
\hline D & 175 \\
\hline E & 10 \\
\hline
\end{tabular}

In the Table2the parameters of simulation use in MATLAB and Solidworksare related, all the values for the thermal constants are calculated by the software respectively

Table2SimulationParameters.

\begin{tabular}{|l|c|}
\hline \multicolumn{1}{|c|}{ Parameter } & Value \\
\hline Velocity,in and out & $0.5\left[\frac{\mathrm{m}}{\mathrm{s}}\right]$ \\
\hline Volumeint. & $0.0073\left[\mathrm{~m}^{3}\right]$ \\
\hline TemperatureSup & $330[\mathrm{~K}]$ \\
\hline Temperatureamb & $293[\mathrm{~K}]$ \\
\hline Air mass & $0.0094[\mathrm{~kg}]$ \\
\hline Exchangerarea & $0.027\left[\mathrm{~m}^{2}\right]$ \\
\hline Total área offood. & $0.036\left[\mathrm{~m}^{2}\right]$ \\
\hline Individual area & $0.0016\left[\mathrm{~m}^{2}\right]$ \\
\hline Initial wáter mass & $0.220[\mathrm{~kg}]$ \\
\hline
\end{tabular}




\section{Results:}

In the proposed model, for 8 hours of simulation, was observed howthe moisture in the food goes falling in linear form until a value of $10 \%$. This is due to working in the linear zone dehydration, where the final moisture must be grater of the critical moist (Figure6).

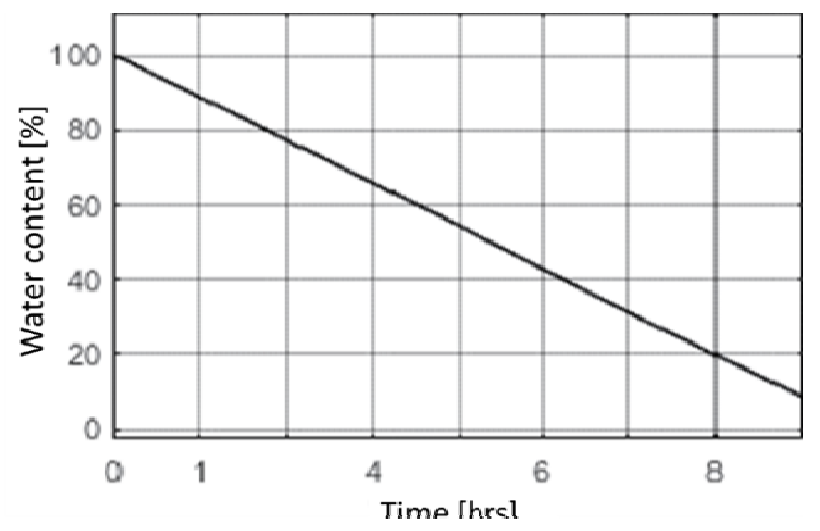

Figure6. Chart of water content [\%] in the food vs time of dehydration.

By simulating the first 100s of dehydration, was observed that the system temperature is established to $311 \mathrm{~K}$, this implies that the air inside the chamber was increased 18 degrees, which is within the range necessary to the dehydration (Figure7).

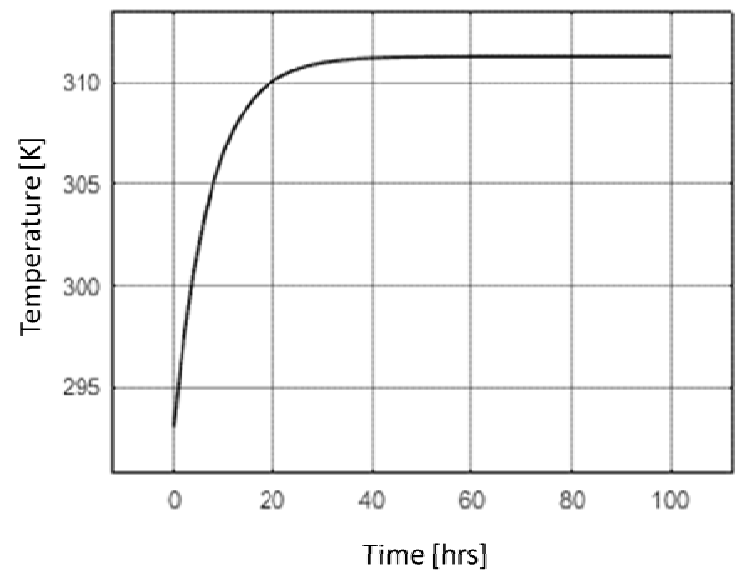

Figure7Chart of temperature [K] vs Time [s]

In contrast, the simulation in CFD, was observed how the temperature varies drastically to the output and in each point of the chamber, this is due to the fluid is no completely homogeneous. Similarly, was observed how the final temperature is less than the obtained in MATLAB.
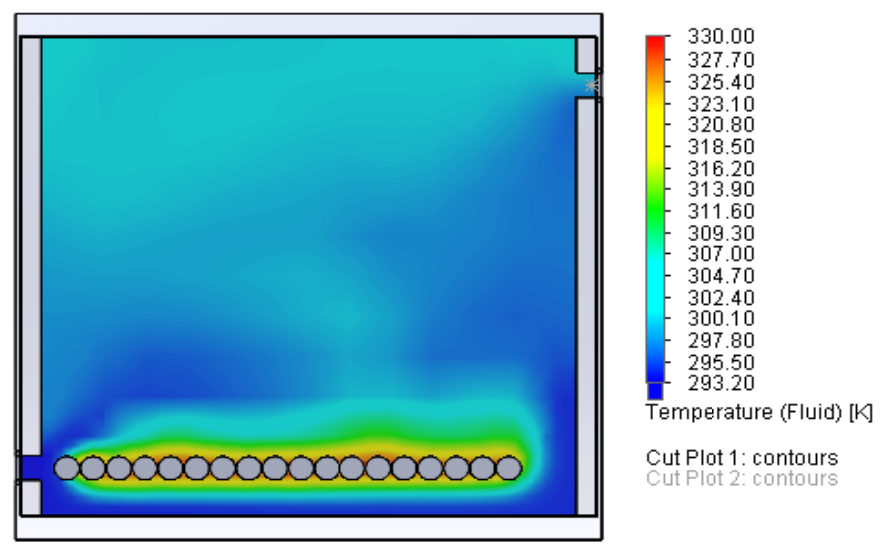

Figure8. Contour of temperature inside the chamber of dehydration. 
Watching the graph of temperature versus time in the Figure9,was observed that the output temperature reach a value of $304 \mathrm{~K}$ and goes falling due to the interaction with the coolest air blast, how is see in the contour of temperatures ofFigure8.

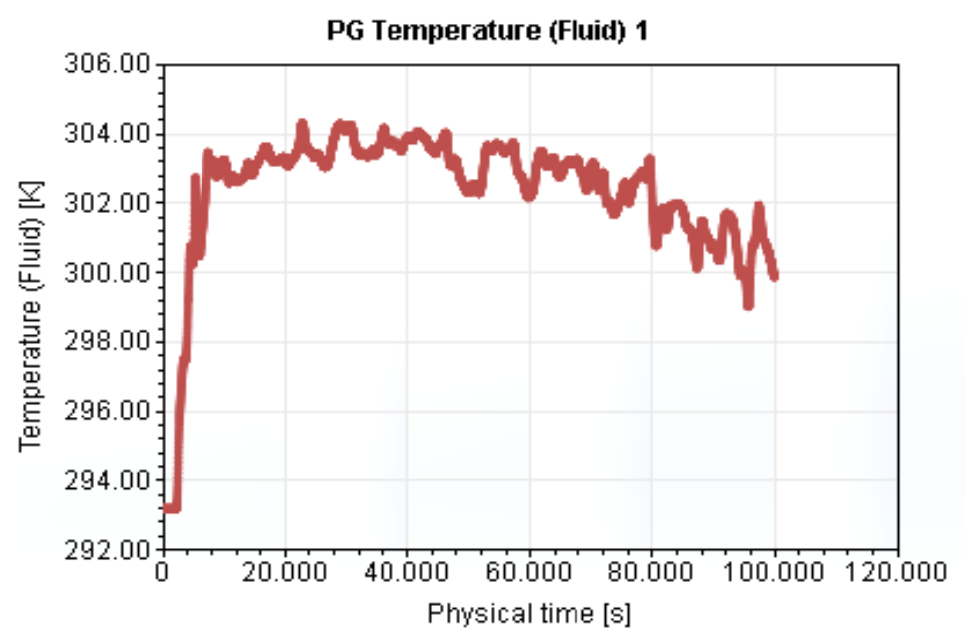

Figure9 Graphof the temperature[K] vs time[s], SolidWorks simulation.

To contrast the final moisture in the food at this temperature, the simulation in MATLAB was executed for $304 \mathrm{~K}$ inside the chamber, which show that the moisture decreases to $45 \%$. With this, a difference in the final content of mass water of $77 \mathrm{~g}$ was determined (Figure10). However, a temperature of $304 \mathrm{~K}$ is within the range necessary to the dehydration.

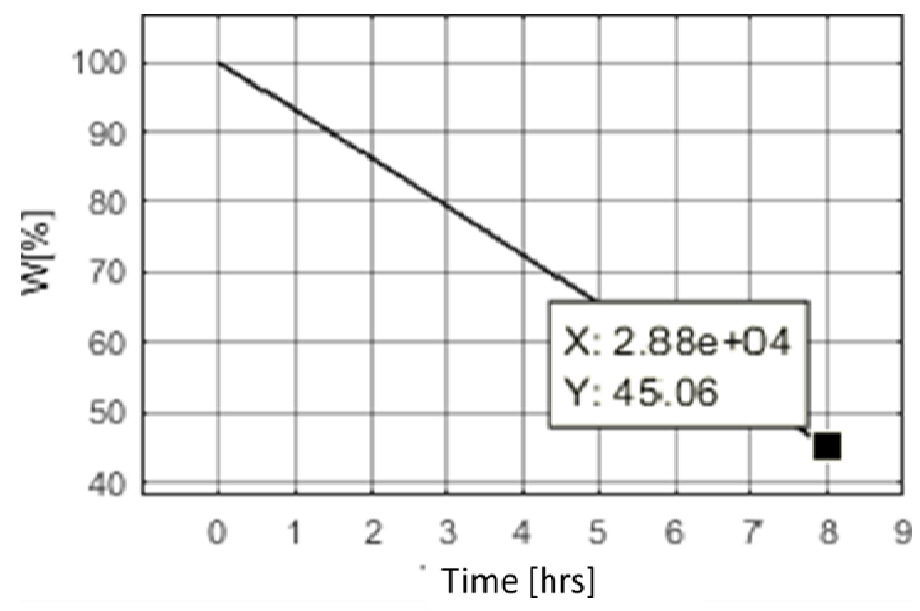

Figure10Chart of watermass [\%] vs time dehydration [s],for304K.

4. Conclusions.

The model developed in this work complies the objective of identifying the process of dehydration. However, when the dynamic of the system is simplified, the accuracy is affected, generating a difference in the temperature between the analytical model an CDF simulation of 7 degrees. This is due to the necessary assumption that the temperature is uniform in the inside of the chamber.

The proposed model showed to be a faster and practice toolwhen it is compared to the demand of computational resource with a simulation like the CFD. Where for a simulation of $8 \mathrm{~h}$ hours of dehydration the model in MATLAB take 40s, in SolidWorks was required $3 \mathrm{~h}$ for 100s of time simulation. This is because of the nature of each simulation, due to the CFD need more calculus by variable than use OED model.

\section{Acknowledgment}

The authors would like to thank the research vice-cancellorshipof Nueva Granada Military Universityfor financing this work (research project IMP-ING-2656, 2018). 


\section{Reference}

[1] D. I. Onwude, N. Hashim, and G. Chen, "Recent advances of novel thermal combined hot air drying of agricultural crops," Trends Food Sci. Technol., vol. 57, pp. 132-145, 2016.

[2] O. Prakash, V. Laguri, A. Pandey, A. Kumar, and A. Kumar, "Review on various modelling techniques for the solar dryers," Renew. Sustain. Energy Rev., vol. 62, pp. 396-417, 2016.

[3] C. L. Hii, C. L. Law, and M. Cloke, "Modeling using a new thin layer drying model and product quality of cocoa," J. Food Eng., vol. 90, no. 2, pp. 191-198, 2009.

[4] Z. Wang et al., "Mathematical modeling on hot air drying of thin layer apple pomace," Food Res. Int., vol. 40, no. 1, pp. 39-46, 2007.

[5] J. Shanthilal and C. Anandharamakrishnan, "Computational and numerical modeling of rice hydration and dehydration: Areview," Trends Food Sci. Technol., vol. 31, no. 2, pp. 100-117, 2013.

[6] A. Durak and U. Akyol, "Modeling of a Hot Air Drying Process by Using Artificial Neural Network Method,” Termotehnica, vol. 1, pp. 51-57, 2013.

[7] M. H. Nadian, M. H. Abbaspour-Fard, A. Martynenko, and M. R. Golzarian, "An intelligent integrated control of hybrid hot airinfrared dryer based on fuzzy logic and computer vision system,” Comput. Electron. Agric., vol. 137, pp. 138-149, 2017.

[8] B. Kumar and I. Factor-, "Analysis of Thermal Performance of Solar Air Dryer for Three Different Absorber," vol. 3, no. 4, pp. 10871092, 2015.

[9] M. Aydin, S. L. Yang, N. Kurt, and T. Yano, "Test of a simple model for estimating evaporation from bare soils in different environments,” Ecol. Modell., vol. 182, no. 1, pp. 91-105, 2005.

[10] C. E. Orrego, Procesamiento De Alimentos, no. 1. 2003.

[11] Z. Berk, Food Process Engineering and Technology, vol. 53, no. 9. 2013.

[12] A. Ayensu, "Dehydration of food crops using a solar dryer with convective heat flow," Sol. Energy, vol. 59, no. 4-6-6 pt 4, pp. 121126, 1997. 